\title{
PERANCANGAN RUANG PUBLIK TERPADU RAMAH ANAK DI LINGKUNGAN PADAT PENDUDUK
}

\author{
Fery Mulya Pratama ${ }^{1}$, Nia Suryani ${ }^{2}$ \\ ${ }^{1}$ Universitas Indraprasta PGRI, Program Studi Arsitektur \\ pratama.ars@gmail.com \\ ${ }^{2}$ Universitas Indraprasta PGRI, Program Studi Arsitektur \\ niasuwardi@gmail.com
}

\begin{abstract}
The City Government is seriously committed to making Bekasi a Child Friendly City (KLA). The municipal government is also trying to improve a number of public facilities to provide rights and protection to children. Meanwhile, in fact, a number of facilities and public open spaces in Bekasi are not fully childfriendly. In fact, there are still many residential areas that do not yet have public space facilities that can accommodate children's play activities and citizen interactions such as in RT 04/06 Cikiwul Village. In this residential area, almost all citizen interaction activities such as mothers chatting, children playing and fathers drinking coffee together are mostly carried out on the terraces of residents' houses, on neighborhood roads, or even only in guard posts which are not used during the day. Children often play on the road by taking advantage of times when no vehicles are passing just to play ball, hide and seek, or play high jump with rubber. This certainly does not provide a sense of security for children and parents and limits creativity and space for them, not to mention that it also disturbs the speed of vehicles passing on this residential neighborhood road. Seeing these conditions, several community leaders and stakeholders such as the head of RT 04 held deliberations and discussions to present a simple public space but still could accommodate children's play activities and citizen interactions so that residents in the RT $04 R W 06$ environment could develop more creatively and happily and fulfilled all the space requirements.
\end{abstract}

Key Words: playground,children, public space

\begin{abstract}
Abstrak : Pemerintah Kota serius berkomitmen menjadikan Bekasi sebagai Kota Layak Anak (KLA). Pemkot pun berupaya membenahi sejumlah fasilitas publik untuk memberikan hak dan perlindungan pada anak. Sementara itu, pada kenyataanya sejumlah fasilitas dan ruang terbuka publik di Bekasi belum sepenuhnya ramah anak bahkan masih banyak kawasan permukiman yang belum memiliki fasilitas ruang publik yang dapat menampung kegiatan bermain anak serta interaksi warga seperti di lingkungan RT 04/06 Kelurahan Cikiwul ini. Di kawasan permukiman ini hampir semua kegiatan interaksi warga seperti ibu-ibu mengobrol, anak-anak bermain serta bapak-bapak minum kopi bersama banyak dilakukan di teras rumah warga, jalan lingkungan, atau bahkan hanya di pos ronda yang tidak digunakan di siang hari.

Anak-anak sering kali bermain di jalan dengan memanfaatkan saat-saat tidak ada kendaraan yang berlalu hanya sekedar untuk bermain bola, petak umpet, atau bermain lompat tinggi dengan karet. Hal ini tentunya tidak memberikan rasa aman bagi anak-anak dan orang tua serta membatasi kreatifitas dan ruang gerak bagi mereka, belum lagi juga mengganggu laju kendaraan yang melintas di jalan lingkungan permukiman ini.

Melihat kondisi tersebut, beberapa tokoh masyarakat dan pemangku kepentingan seperti ketua RT 04 melakukan musyawarah serta diskusi untuk menghadirkan sebuah ruang publik sederhana namun tetap dapat mewadahi aktivitas bermain anak dan interaksi warga sehingga warga di lingkungan RT 04 RW 06 ini bisa lebih berkembang kreatif dan bahagia serta tercukupi semua kebutuhan ruangnya.
\end{abstract}

Kata Kunci : ruang bermain,anak,ruang publik

\section{PENDAHULUAN \\ Analisis Situasi}

Bekasi direncanakan untuk menuju Kota Layak Anak (KLA). Pemkot pun berupaya membenahi sejumlah fasilitas publik untuk memberikan hak dan perlindungan pada anak. Wakil Wali Kota Bekasi Tri Adhianto Tjahyono mengungkapkan bahwa anak merupakan generasi penerus bangsa yang memiliki peran strategis dalam pembangunan bangsa dan negara pada masa yang akan datang. Anak perlu mendapatkan kesempatan yang seluas-luasnya untuk hidup tumbuh dan berkembang secara wajar baik fisik, mental, maupun sosial serta terhindar dari perlakuan tindakan yang salah. Adanya Tim Gugus Tugas Kota Layak Anak diharapkan dapat meningkatkan komitmen untuk mengimplementasikan kebijakan yang berkaitan 
dengan pemenuhan hak anak, sehingga dapat menciptakan anak-anak yang berkualitas, berintegritas dan berakhlaqul kharimah sebagai modal pembangunan bangsa.

Sementara itu, pada kenyataanya sejumlah fasilitas dan ruang terbuka publik di Bekasi belum sepenuhnya ramah anak bahkan masih banyak kawasan permukiman yang belum memiliki fasilitas ruang publik yang dapat menampung kegiatan bermain anak serta interaksi warga seperti di lingkungan RT 04/06 Kelurahan Cikiwul ini. Di kawasan permukiman ini hampir semua kegiatan interaksi warga seperti ibu-ibu mengobrol, anak-anak bermain serta bapak-bapak minum kopi bersama banyak dilakukan di teras rumah warga, jalan lingkungan, atau bahkan hanya di pos ronda yang tidak digunakan di siang hari.

Anak-anak sering kali bermain di jalan dengan memanfaatkan saat-saat tidak ada kendaraan yang berlalu hanya sekedar untuk bermain bola, petak umpet, atau bermain lompat tinggi dengan karet. Hal ini tentunya tidak memberikan rasa aman bagi anak-anak dan orang tua serta membatasi kreatifitas dan ruang gerak bagi mereka, belum lagi juga mengganggu laju kendaraan yang melintas di jalan lingkungan permukiman ini.

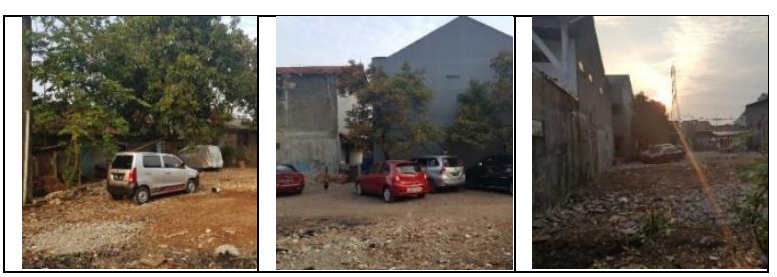

Gambar 1 Kondisi Eksisting dan Lingkungan Sekitar RPTRA

\section{Permasalahan Mitra}

Melihat kondisi tersebut, beberapa tokoh masyarakat dan pemangku kepentingan seperti ketua RT 04 melakukan musyawarah serta diskusi untuk menghadirkan sebuah ruang publik sederhana namun tetap dapat mewadahi aktivitas bermain anak dan interaksi warga sehingga warga di lingkungan RT 04 RW 06 ini bisa lebih berkembang kreatif dan bahagia serta tercukupi semua kebutuhan ruangnya. Dari hasil diskusi dan musyawarah tersebut terdapat kesepakatan akan menggunakan sebidang tanah milik warga untuk bisa digunakan sebagai ruang publik sederhana tersebut, namun baik warga maupun tokoh masyarakat ini belum memiliki pengetahuan bagaimana menrancang sebuah ruang publik yang bisa mengakomodir semua kebutuhan warganya secara efektif disesuaikan dengan keadaan lahan yang ada dan dana yang tersedia. Melihat kondisi ini, kami sebagai tim pengabdian masyarakat Universitas Indraprasta PGRI melakukan diskusi dengan Ketua RT 04 RW 06 Kelurahan Cikiwul dan memberanikan diri melakukan pengabdian masyarakat dengan judul PKM Ruang Publik Terpadu Rramah Anak di Lingkungan RT 04/06 Cikiwul Bantargebang Bekasi.

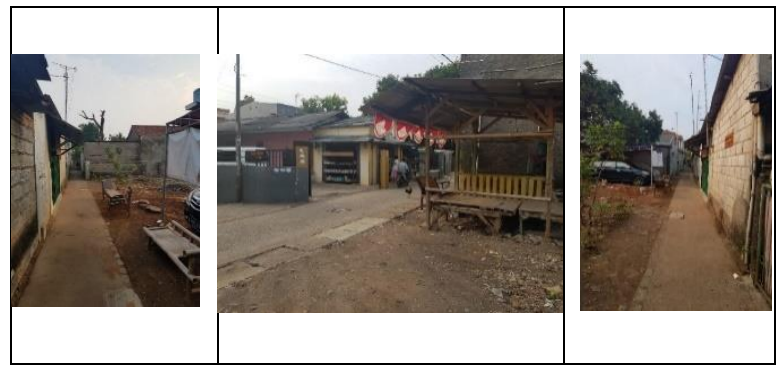

Gambar 2 Area Sekitar Tapak

\section{Tujuan Kegiatan}

Kegiatan ini dilakukan dengan tujuan untuk memberikan usulan desain Ruang Publik Terpadu Ramah Anak yang sesuai dengan karakter dan kebutuhan penggunanya terutama di Lingkungan RT 04/06 Cikiwul Bantargebang Bekasi.

\section{METODOLOGI}

Kegiatan yang dilakukan diawali dengan menjalin komunikasi dengan mitra untuk meminta kesediaan kerjasama dalam Program Pengabdian Masyarakat LPPM Universitas Indraprasta PGRI Jakarta. Selanjutnya melakukan survey lokasi yang lebih detail ke lingkungan RT 04 RW 06 Cikiwul Bantargebang Bekasi untuk melihat keseharian warga dan kondisi lahan (yang akan dijadikan RPTRA nanti) saat ini, menemukan permasalahanpermasalahan dan menentukan langkah-langkah yang akan dilakukan ke depannya terkait dengan kegiatan pengabdian ini. Waktu pelaksanaan Pengabdian masyarakat direncanakan pada Bulan April 2020. Pelaksanaan kegiatan abdimas ini dilakukan langsung oleh warga karena metode yang digunakan adalah participatory. Metode ini dipilih agar warga bisa ikut serta terjun langsung dalam proses mendesain sehingga desainnya akan tepat sasaran dan didukung dengan rasa memiliki hingga nanti desain tersebut bisa terbangun. 


\section{HASIL DAN PEMBAHASAN Analisis Lingkungan Sekitar}

Berbekal analisis situasi awal dan dikusi dengan mitra, kami tim pengusul melakukan observasi secara lebih mendalam mengenai keseharian warga dan kebutuhan akan ruang public. Dari hasil pemetaan fungsi bangunan Kawasan permukiman, kami menemukan fungsi bangunan terdiri dari rumah tinggal, rumah tinggal yang memiliki kontrakan dan rumah kontrakan. Hasil ini menjawab temuan mengapa segmen pengguna ruang publik yang di dominasi oleh keluarga muda baik warga tetap maupun sementara yang memiliki anak kecil. Dari hasil pemetaan ini kami juga menemukan kondisi anak anak yang bermain dijalan depan rumah mereka, dan ibu ibu ngobrol di depan rumah mereka sebagai bentuk budaya kebertetanggan. walaupun sebetulnya aktivitas public yang digunakan tidak layak, namun ada beberapa ruang terbuka yang berpotensi menjadi ruang terbuka publik.

Berdasarkan wawancara mendalam dengan warga setempat yang memiliki anak kecil, kami mendapatkan informasi terdapat kecemasan tersendiri terutama para ibu yang saat Anakanaknya berlarian, bermain bola, bersepeda, di jalanan suatu saat terserempet motor. Kondisi ini memicu perilaku kecenderungan para ibu selalu berteriak saat anaknya terlalu asik bermain saat ada kendaraan melintas atau memilih mengurung anaknya di dalam rumah saat harus mereka tidak dapat mengawasi. Hasil temuan lainnya adalah beberapa orangtua memilih untuk cuek membiarkan anak mereka bermain di jalan karena ada teman yang dianggap bisa diandalkan atau mempercayakan pada anaknya bisa menjaga diri sendiri walau masih kecil.

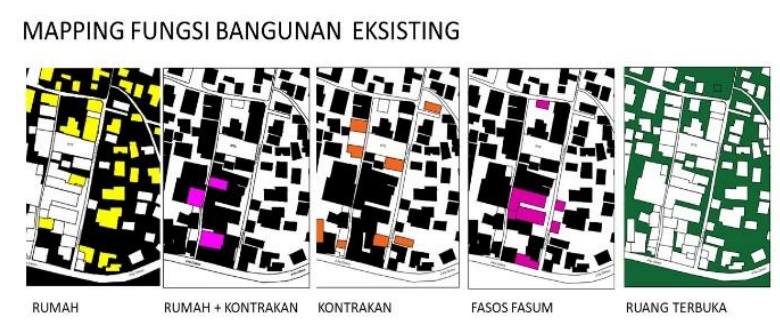

Gambar 3 Mapping Fungsi Banguan Eksisting

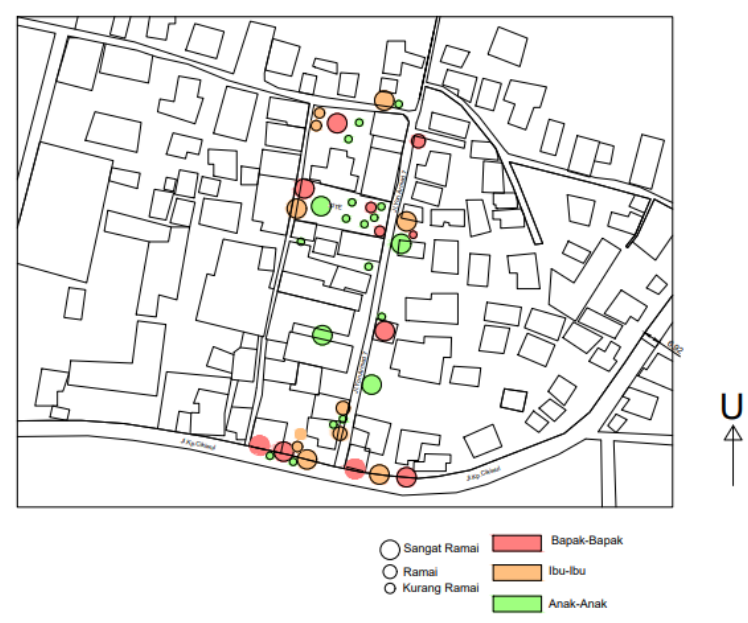

Gambar 4 Mapping aktifitas warga dan intensitasnya

Dari hasil mapping aktifitas warga didapatkan kesimpulan actor yang paling dominan menggunakan ruang public adalah anak anak, kemudian ibu ibu, baru terakhir bapak bapak dan memiliki pola titik aktifitas dekat dengan ruang terbuka. Titik terbaik yang dijadikan ruang bermain anak adalah sebuah ruang terbuka yang disebut warga sebagai "kebon". Lokasi kebon sendiri merupakan sebuah lahan yang dimiliki warga namun belum terbangun dan dimanfaatkan warga untuk menyewa lahan parkir mobil mereka, membuang puing bongkaran bangunan warga, dan menjadikannya kebun tanaman produktif.

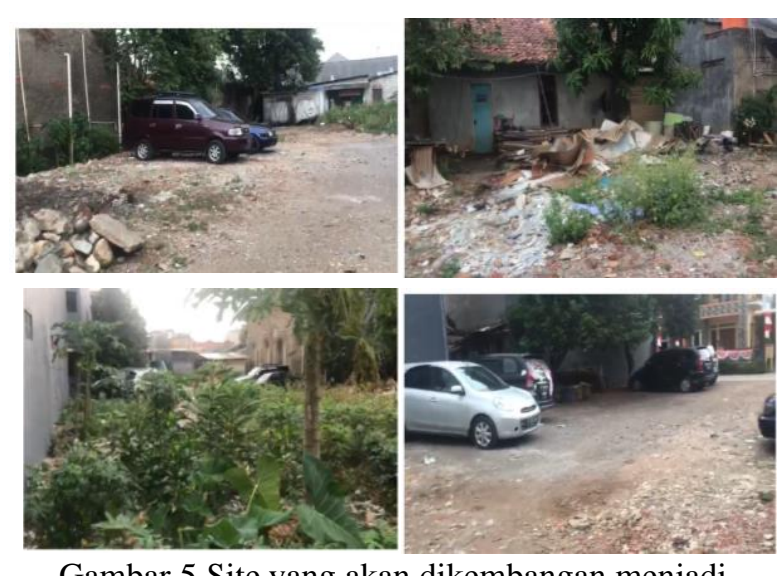

Gambar 5 Site yang akan dikembangan menjadi RPTRA

Pemilihan site atau lahan pengembangan RPTRA ini sangatlah strategis di RT 04 karena letaknya dengan sekolah dasar yang tidak memiliki lapangan untuk anak bermain, berada di tengah permukiman warga yang banyak dikelilingi anak kecil, dan pemilik lahan yang kooperatif untuk meminjamkan lahannya untuk jangka Panjang. Untuk lebih memahami potensi site berikut adalah analisis kondisi sitenya. 


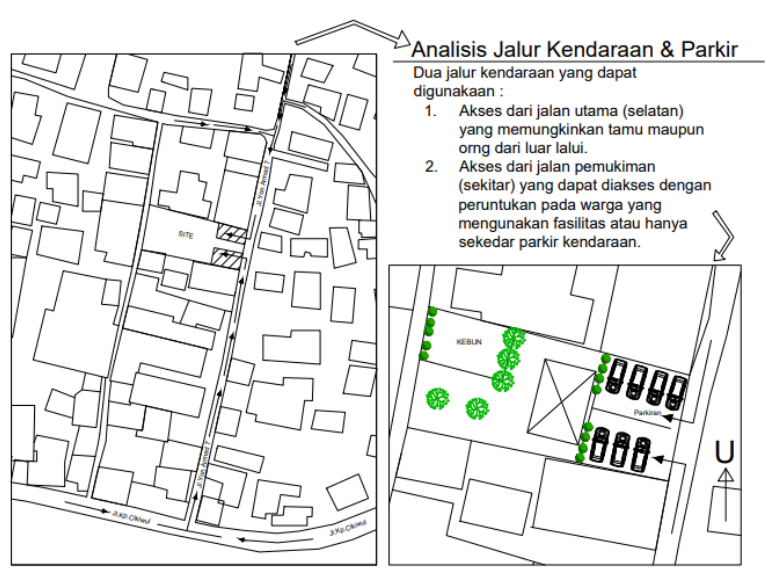

Gambar 6 Analisis sirkulasi kendaraan dan parkir

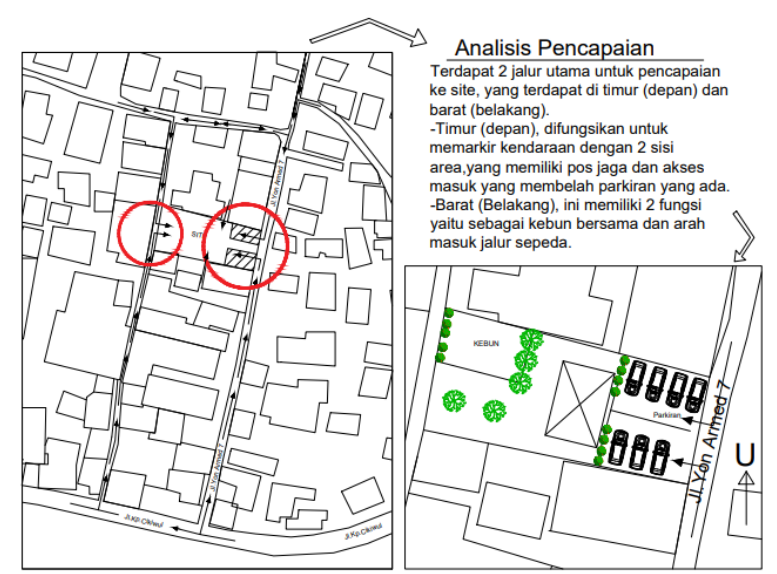

Gambar 7 Analisis pencapaian tapak

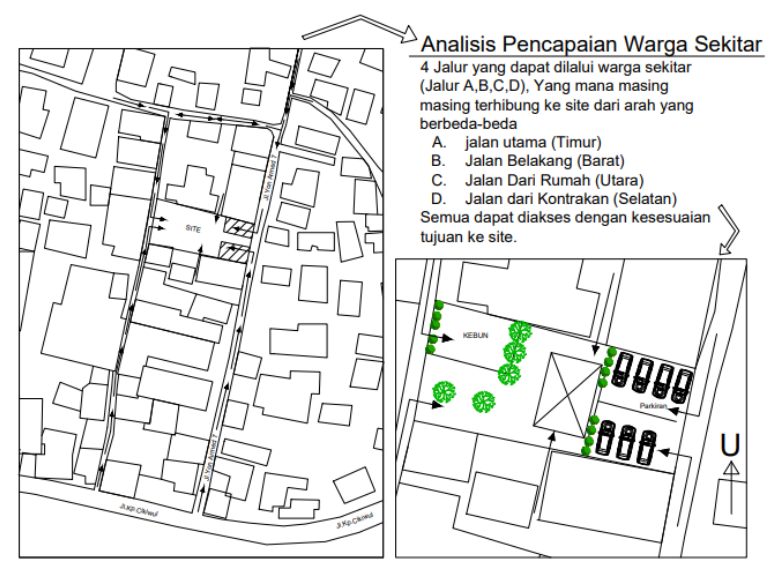

Gambar 8 Analisis pencapaian warga sekitar

Setelah melakukan analisis terhadap posisi site, langkah selanjutnya adalah melakukan analisis kondisi iklim tapak seperti memahami arah edar matahari dan kaitannya terhadap aktifitas yang dikembangkan di dalam tapak serta pertimbangan tata guna lahan di dalamnya seperti yang tertuang pada analisis di bawah ini:

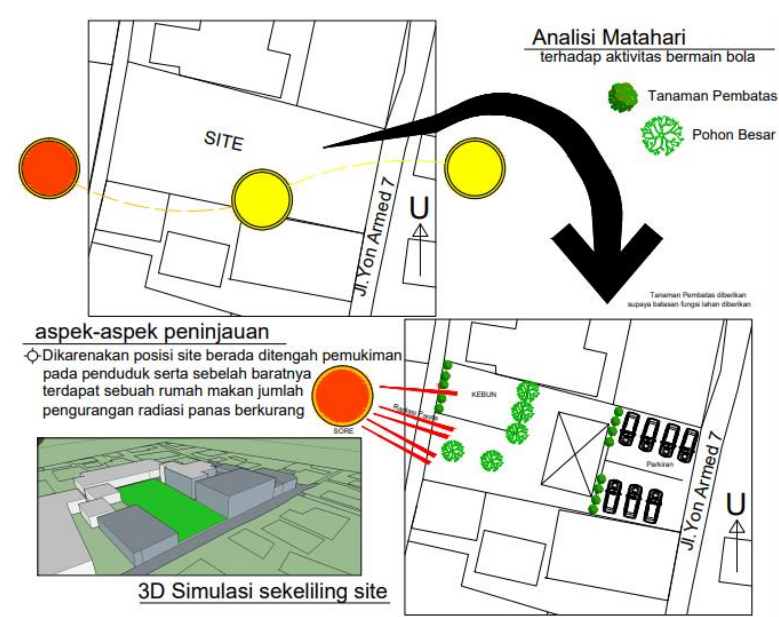

Gambar 9 Analisis arah edar matahari

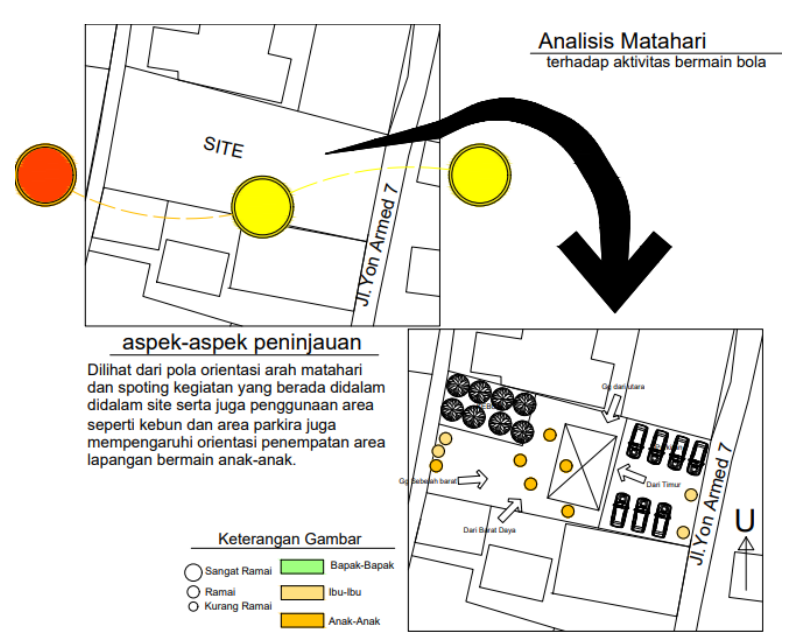

Gambar 10 Analisis arah edar matahari

\section{Usulan Desain RPTRA}

Dari hasil penelusuran kondisi tapak dan kebutuhan aktivitas pada ruang public maka kami mengusulkan desain RPTRA dengan prioritas user adalah anak anak dan para ibu yang mengawasi anaknya bermain sambal beraktifitas. Secara spesifik kami mengusulkan aktifitas di dalamnya berupa track sepeda dan lapangan bermain serbaguna yang dilengkapi tempat untuk duduk duduk, kebun edukasi anak, namun juga tidak mengalahkan kepentingan warga yang menyimpan mobilnya di dalam site beserta pos ronda eksisting yang diperbaharui. Di dalam site juga ditambahkan pepohonan rindang agar ruang public ini menjadi lebih sejuk dan nyaman untuk digunakan warga. Secara lebih detail berikut adalah konsep desain berdasarkan analisis temuan di lapangan 


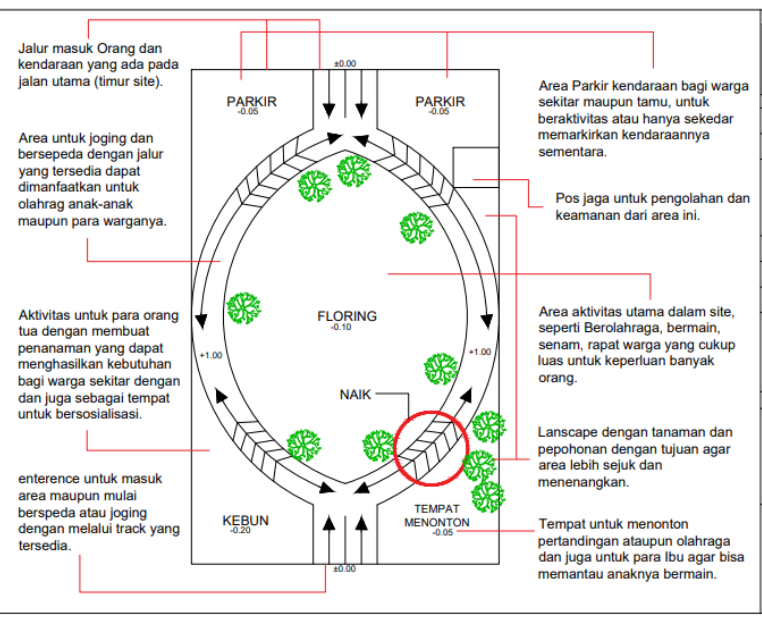

Gambar 11 Konsep pengembangan fungsi lahan

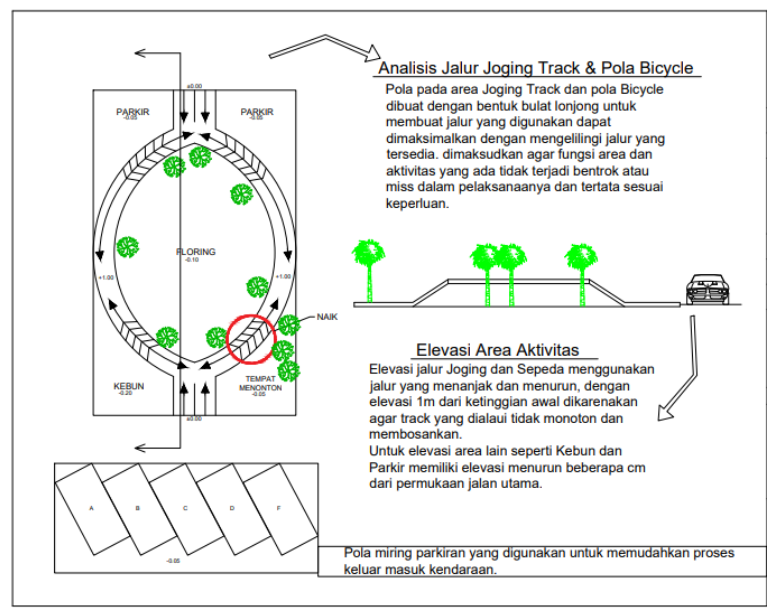

Gambar 12 Konsep rekayasa kontur lahan

Setelah konsep desain disepakati maka tahapan selanjutnya dilakukan dengan membuat produk desain final. Kekuatan utama desain ini terletak pada jalur sepeda bagi anak yang dibuat naik turun dengan mempertimbangkan keamanan berkendara namun tetap menarik bagi anak anak untuk bermain naik turun di jalur sepeda ini. Ditengah jalur sepeda yang melingkar mengelilingi site terdapat sebuah lapangan serbaguna yang dapat digunakan anak anak bermain bola, bermain layangan, juga dapat dilintasi anak anak bermain sepeda, jogging bagi warga, kegiatan lomba 17 agustusan atau kegiatan public lainnya. Peletakan pepohonan sebagai vegetasi peneduh terpusat pada bagian barat site sebagai pelindung sengatan matahari sore, sedangkan pada bagian lainnya di dominasi pohon pengarah seperti palem yang mengikuti pola jalur sepeda. Kebun bumbu dapur dan tanaman produktif lainnya tetap kami pertahankan, namun disesuaikan dan ditata ulang sesuai konsep desain. Keberadaan kebun ini juga digunakan sebagai sarana edukasi anak anak untuk mengenalkan kecintaan terhadap lingkungan, mengenal jenis jenis tumbuhan beserta manfaatnya. Bagian eksisting lainnya yang kami akomodir adalah keberadaan pos ronda yang jadi tempat berkumpulnya bapak bapak di sore hari juga sebagaimana Namanya berfungsi sebagai pos ronda pada malam hari. Selain itu juga terdapat parkiran mobil warga yang jumlahnya disesuaikan jumlah mobil pengguina yaitu 5 buah.

Untuk memudahkan warga membaca produk desain dan mengaplikasikannya saat pembangunan, kami tidak menggunakan format gambar kerja yang rumit. Kami memberikan gambar yang mudah dibaca berupa gambar rencana tapak yang sudah diberi grid atau garis bantu yang berjarak per 1 meter. Keberadaan gambar ini akan sangat membantu warga untuk melihat ilustrasi posisi ruang sesuai kondisi di lapangan dan memudahkan warga jika akan membuat penyesuaian desain. Gambar pendukung pun disiapkan berupa potongan kontur tapak sehinnga dapat dibayangkan aplikasinya juga gambar ilustrasi desain 3 dimensi beserta keterangan material serta warna yang digunakan.

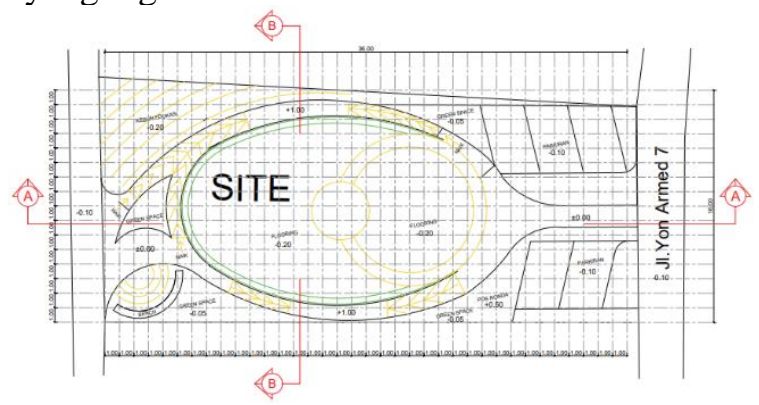

Gambar 13 Gambar Rencana Tapak

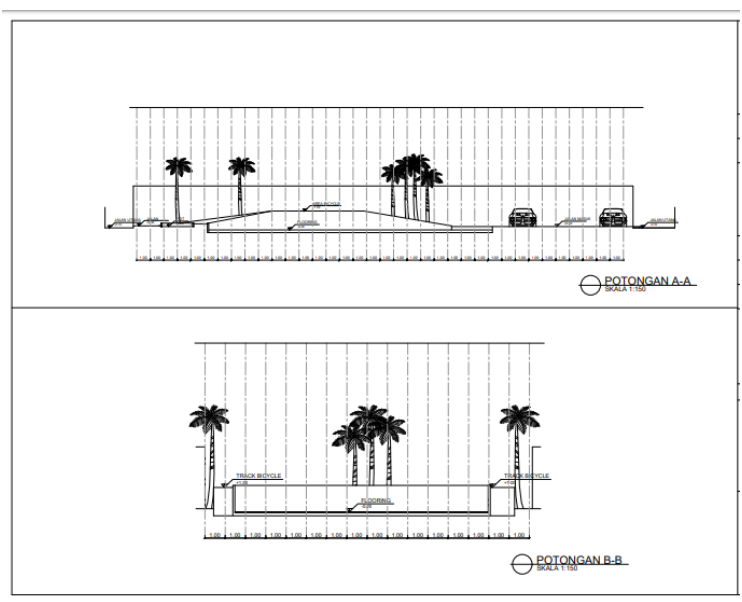

Gambar 14 Gambar potongan Tapak 
Berikut ini adalah gambar visualisasi tiga dimensi dari perencanaan RPTRA di Rt 04 kelurahan Cikiwul. Keberadaan gambar visual 3d bertujuan membuat warga melihat ilustrasi kondisi saat ini dan stelah dibangun nanti, sekaligus penyempurna produk desain yang kami usulkan.

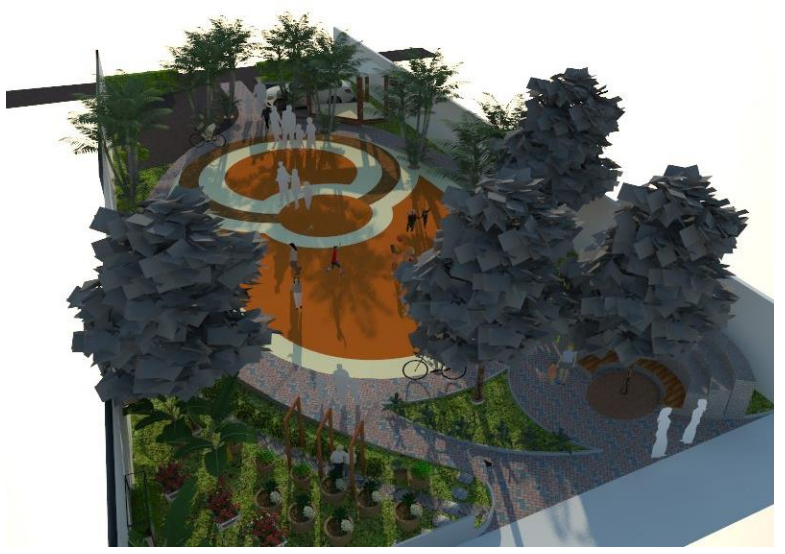

Gambar 15 Ilustrasi desain situasi lingkungan RPTRA
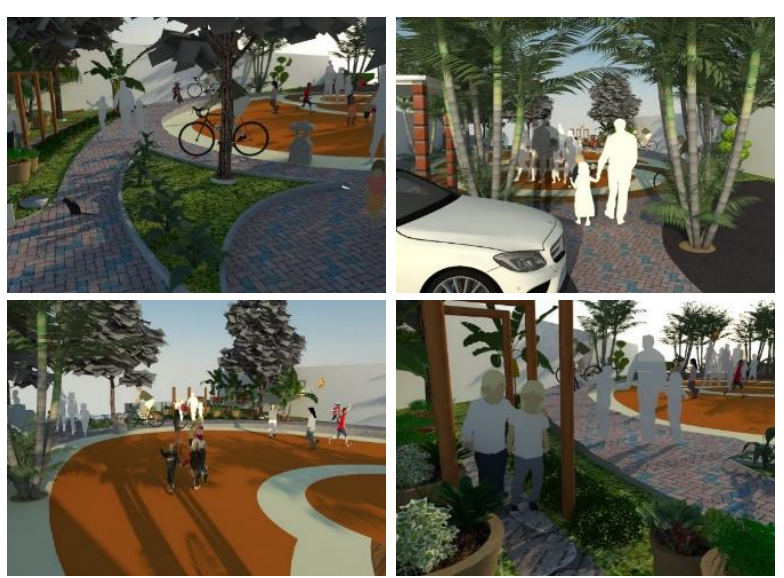

Gambar 16 Ilustrasi suasana di dalam RPTRA

\section{PENUTUP}

\section{Simpulan dan Saran}

Dari pelaksanaan kegiatan abdimas ini yang dilakukan langsung oleh warga karena metode yang digunakan adalah participatory dapat terlihat desain yang dihasilkan bisa lebih tajam menjawab permasalahan yang dihadapi mitra. Metode ini dipilih agar warga bisa ikut serta terjun langsung dalam proses mendesain sehingga desainnya akan tepat sasaran dan didukung dengan rasa memiliki hingga nanti desain tersebut bisa terbangun.

\section{DAFTAR PUSTAKA}

Arendt, H. (1986). Communicative Power. In S. Lukes (Ed.), Power. . Oxford: Basil Blackwell Ltd.

Cowen, M., \& Shenton, R. (1996). Doctrines of Development. London: Routledge.

De Certeau, M. (1993). Walking in the City. In S. During (Ed.), The Cultural Study Reader. . London and New York: Routledge.

Elyda, C., \& Budiari, I. (2015, September 17). Jakartans Enthused with New RPTRA COmmunity Centers. The Jakarta Post.

Jones, P., Petrescu, D., \& Till, J. (2012). Architecture and Participation. London and New York: Routledge. Lefebvre, H. (1996). Writing on Cities. Oxford: Blackwell Publisher

PPA, B. (2014). Proposal. Jakarta: Badan Pemberdayaan Masyarakat, Perempuan dan Keluarga Berencana

Sanders, Elizabeth B-N; SonicRim. (2002). From User-Centered to Partisipatory Design Approach. Dalam J. Frascara, Design and Social Sciences: Making

Connections. London And New York: taylor and Francis

https://megapolitan.kompas.com/read/20

17/06/28/15092351/satu.lagi.fasilitas.publik.rptra. kemuning.hadir.di.pejaten.timur. 